\title{
Research Paper: \\ Cloning and Expression of Serratia Marcescens Prodigiosin Gene in Ecoli XL1blue
}

\author{
Maryam Akbari ${ }^{1}$ (1), *Kumarss Amini ${ }^{1}$ (1)
}

1. Department of Microbiology, Faculty of Science, Saveh Branch, Islamic Azad University, Saveh, Iran.

Citation Akbari M, Amini K. Cloning and Expression of Serratia Marcescens Prodigiosin Gene in Ecoli XL1blue. Jundishapur Journal of Medical Sciences. 2021; 20(2):102-111. https://doi.org/10.32598/JSMJ.20.2.1

dol' https://doi.org/10.32598/JSMJ.20.2.1

Received: 22 Jun 2020 Accepted: 08 Nov 2020 Available Online: 01 Jun 2021

Keywords:

Serratia marcescens, Prodigiosin, Cloning, Bacterial pigments, Real Time PCR

\section{ABSTRACT}

Background and Objectives: Serratia is a gram-negative bacterium. The pigmentation property of Serratia Marcescens is used as a marker of dust particles in the environment and in the hospital. Today biopigments are also widely used in the manufacture and production of pharmaceutical products. Prodigiosin is a promising drug due to its reported properties of antifungal immunosuppressive and antiproliferative activities. In the present study, cloning of pig gene- isolated from Serratia Marcescens in Ecoli XL1blue was performed.

Subjects and Methods 60 Samples were taken from clinical sources of patients hospitalized with urinary tract infections in Saveh Hospitals. Serratia Marcescens were identified and isolated by different tests. The pig gene was cloned by T-A cloning using PTG-19 vector into the Escherichia coli XL1blue as host. Expression of cloned gene in recombinant colonies was evaluated by Real time PCR. The phylogenetic tree was plotted using clustalX and Mega5 software

Results Screening of samples identified 12 isolates of Serratia Marcescens from then 4 isolates had pig gene. Expression of Pig gene in Escherichia coli XL1blue was confirmed by Real-Tima PCR. As a result of phylogenetic studies, some close relatives of serratia have been identified as candidates for further studies Conclusion Serratia Marcescens can be considered as a rich source of pigments with many applications and can be used as indigenous strains to produce Prodigiosin.

\section{* Corresponding Author:}

Address: Department of Microbiology, Faculty of Science, Saveh Branch, Islamic Azad University, Saveh, Iran.

Tel: +98 (912) 54524074

E-Mail: kamini@iau.saveh.ac.ir 


\title{
كلوينيَّ و بيان رُن يرودى جيوسين استخر اجشده از سر اشيا مارسنس در باكترى Ecoli XL1blue
}

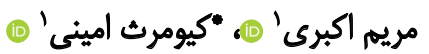

ا. أكروه ميكروبيولوزى، دانشكده علوم يايه، واحد ساوه، دانشكاه آزاداد اسلامى، ساوه، ايران.

\begin{abstract}
هيكيده

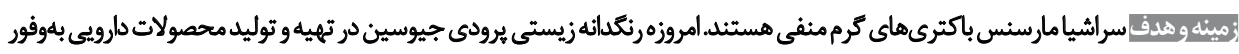

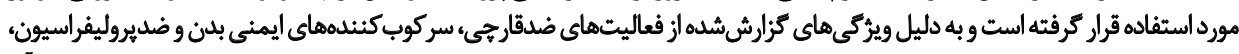

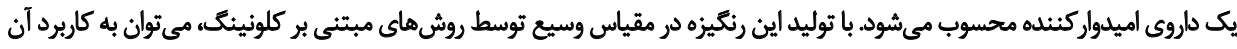

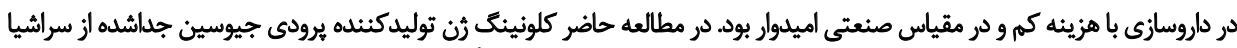

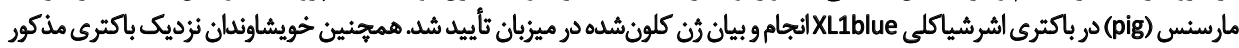
جهت مطالعات آينده معرفى شدئد.

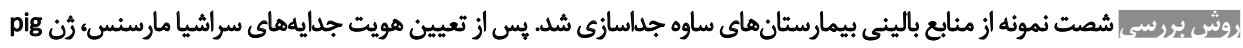

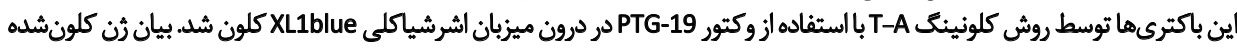

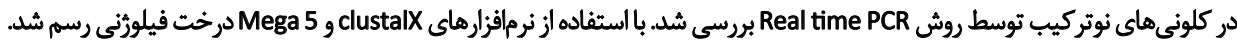

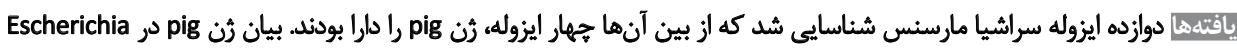

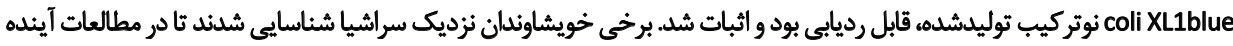

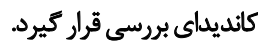

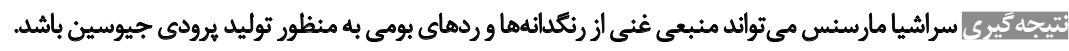

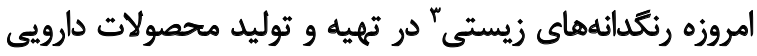

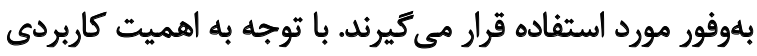

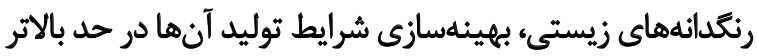

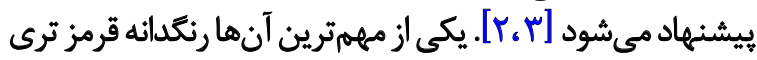

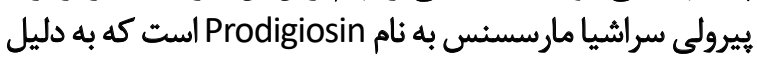

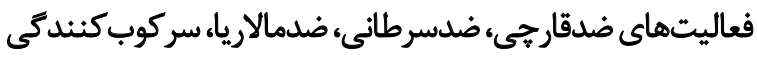

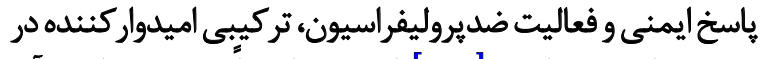

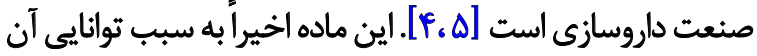

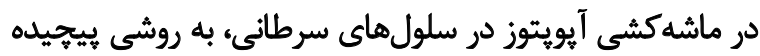

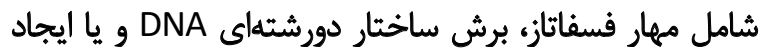

سراشيا' از خانواده آنتروباكترياسه و يك باكترى كرم منفى،

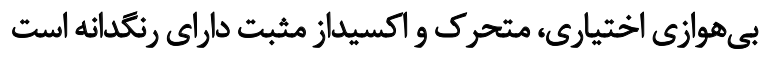

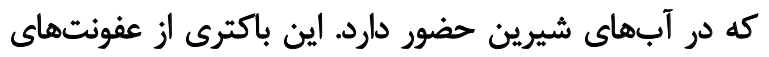

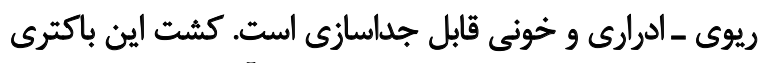

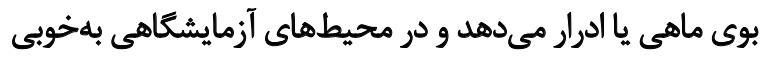

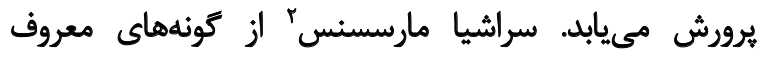

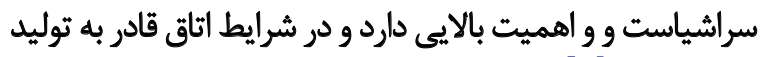

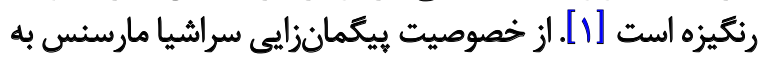

\section{Serratia \\ 2. Serratia marcescens}

… 
با استفاده از برايمرهاى ثن يرودى جيوسين (جدول شماره )

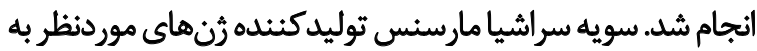
عنوان كنترل مثبت در نظر كرفته شد.

\section{TA Cloning}

به منظور كلون كردن محصول PCR، از كيت - PCR TA-Clon

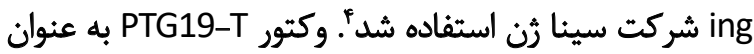

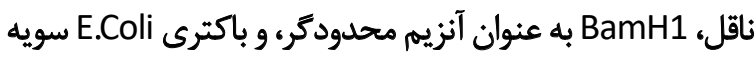

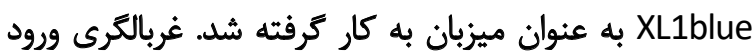

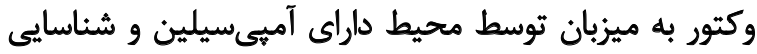

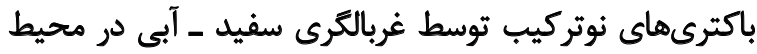

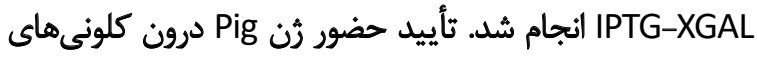

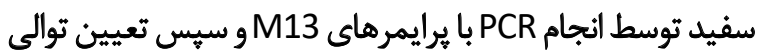

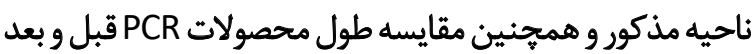
از ازجام فرايند كلوئينگ انجام شد.

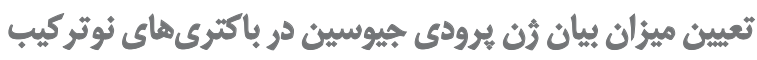

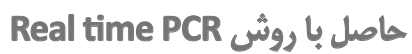
كبه منظور تأييد كارايى فرايند كلونينگ، لازم است كه بيان ثرن

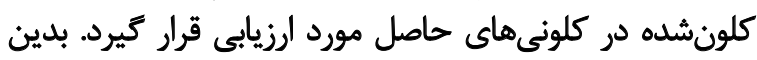

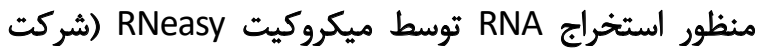
نائ (Qiagen

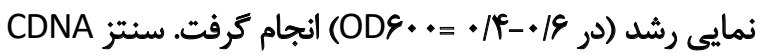
با استفاده از آنزيم AMV Reverse Transcriptase Real Time PCR

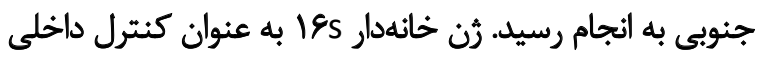

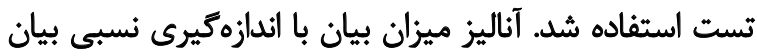

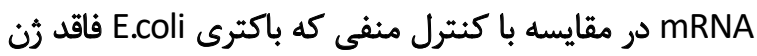
يرودى جيوسين بود، انجام شد.

\section{رسمر درخت فيلورثنى}

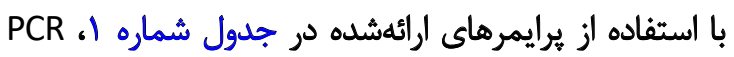

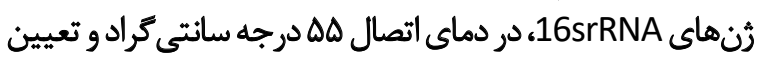

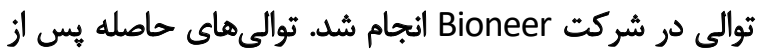

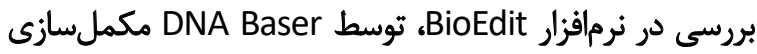

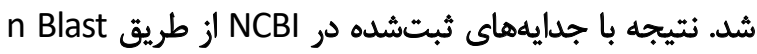

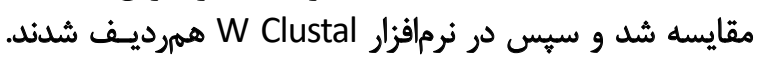

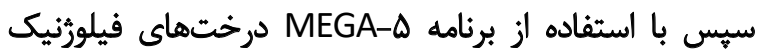

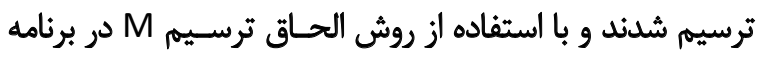

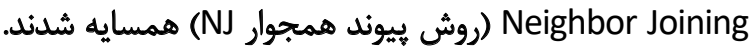

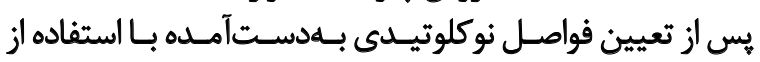

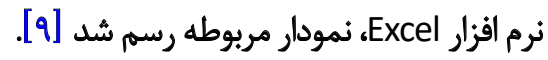

اختلال در شيب pH موجود در غشا، مورد توجه قرار كرفته است.

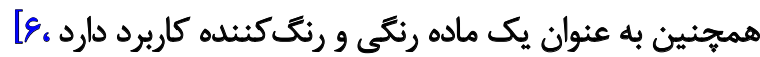

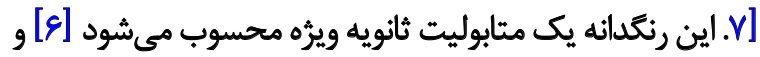

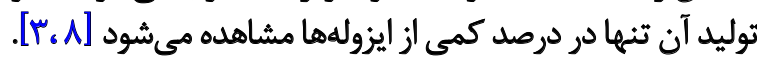

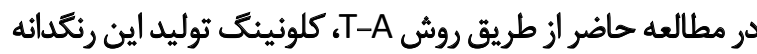

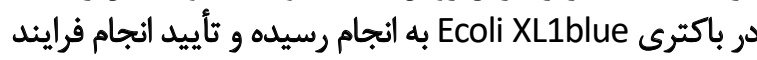

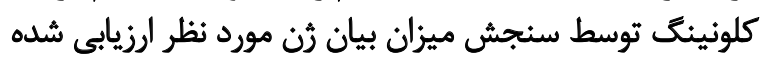

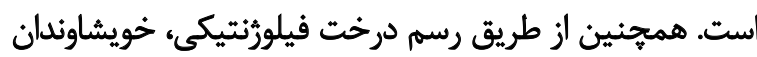

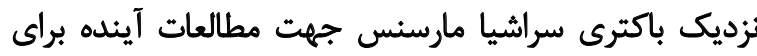

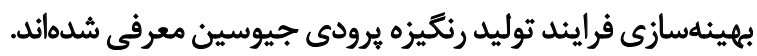

\section{روش بررسى}

$$
\text { نمونهبردارى }
$$

صد نمونه از منابع بالينى بيماران بسترى داراى عفونت ادرارى

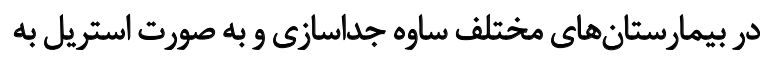
آزمايشكاه ميكروبشناسى منتقل شدن

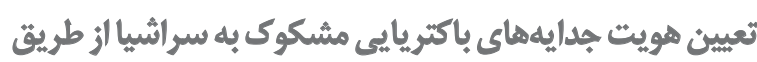

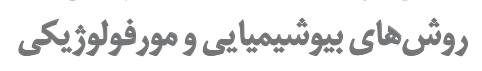

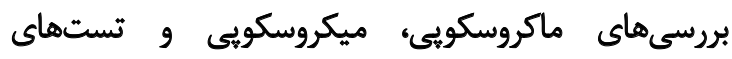

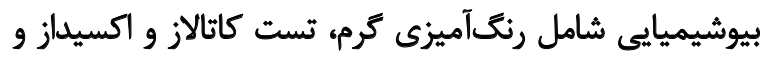

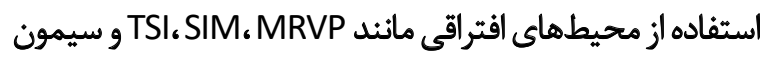

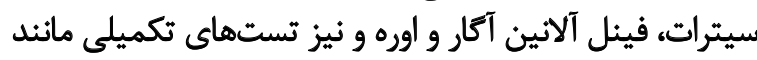

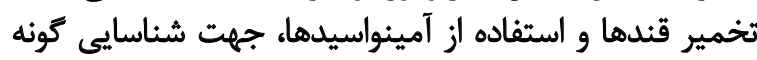

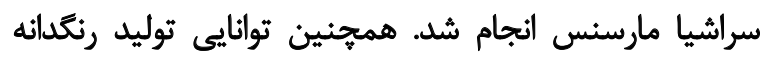

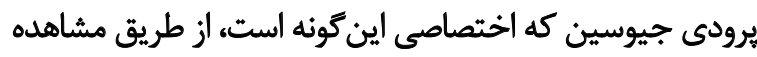
رنك قرمز در كلونى ها، تاييد شد.

تعيين هويت جدايلهاي باكتريايي مشكوك به سراشيا از طريق

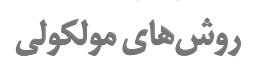

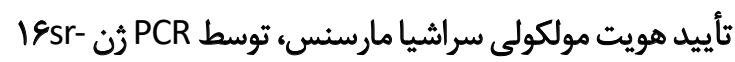

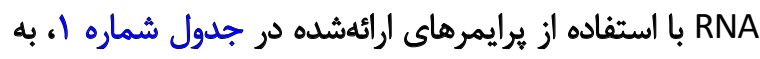

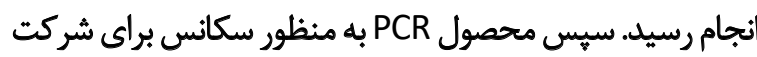

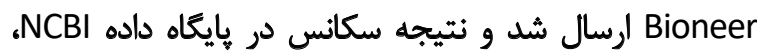
شدBLAST

• كلون كردن رين رنحدائه يرودى جيوسين در باكترى Ecoli XL1blue • شناسايى رثن Pig توسط واكنش PCR

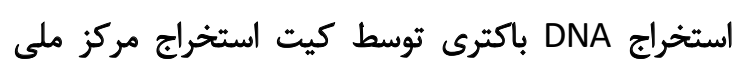

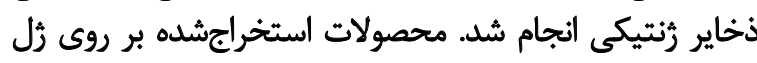

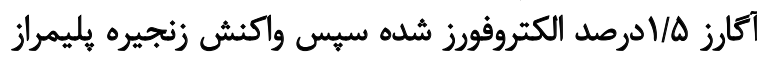


16srRNA gis جدول الـ برايمرهاي مورد استفاده در تكثير رنهاي

\begin{tabular}{|c|c|}
\hline Primer Name & Primer Sequence \\
\hline PigA F & TCGGCATGTCCTTCTCGCTCT \\
\hline Pig A R & CCTGGCATCCCTTTCTCGAGCA \\
\hline 16srRNA F & AGAGTTTGATCCTGGCTCAG \\
\hline 16srRNA R & AAGGAGGTGATCCAGCCGCA \\
\hline
\end{tabular}

در اين مرحله از دوازده ايزوله سراشيا مارسنس جداسازىشده

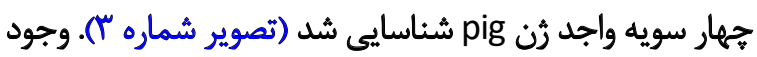

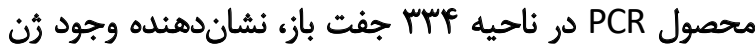

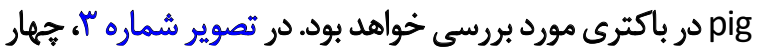

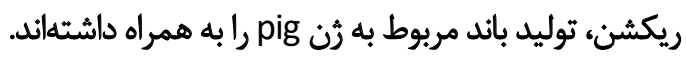

• •وليد كلونهاي نوتركيب در T-A Cloning

حضور كلونىهاى سفيد و آبى در تصوير شماره F نشان داده

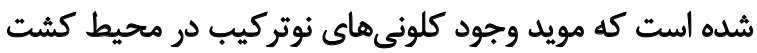

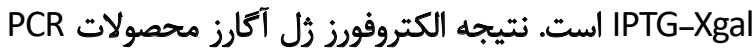
توليدشده توسط يرايمرهاى M13، قبل و بعد از فرايئ كلونينگ

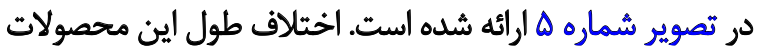

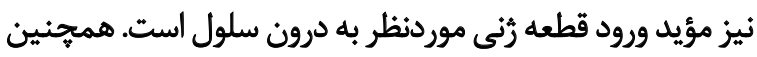

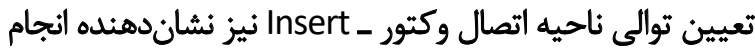

$$
\text { نوتركيب در سلول است (تصوير شماره \&). }
$$

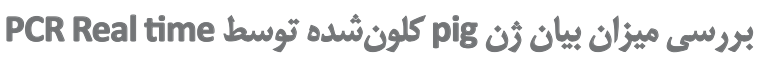
نتايج استخراج RNA در تصوير شماره V نشان داده شده است.

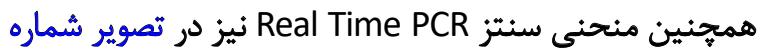
A ارائه شده است. همانين منحني كه در اين تصوير مشخص است،

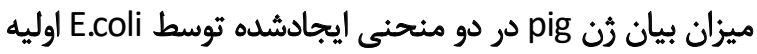

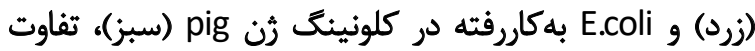

Latọ

تعيين هويث جدايههاي باكتريايي مشكوى به سراشيا از طريق ووث فاى بيوشيميايت و مورفولوزيكى

نتايج كشت سلولهاي سراشيا مارسنس در تصوير شيماره 1

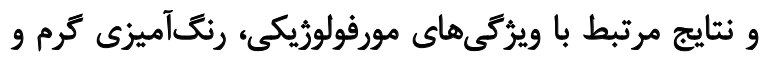

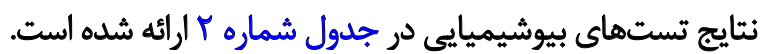

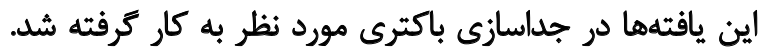

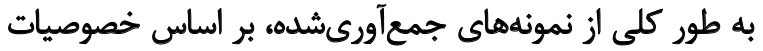
مورفولوزيك، ميكروسكويى و تستهاي بيوشيميايى، دوازيى دوانه

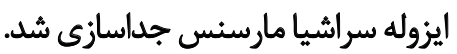

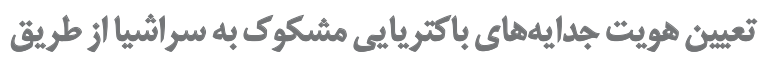

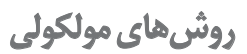

فرايند BLAST انطباق توالي حاصل از تعيين توالي سنكر رابا

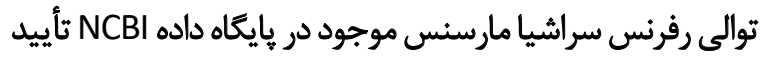
كرد (تصوير شماره برئ سراشيا مارس

• كلون كردن رثن رنكدانه يرودى جيوسين در باكترى Ecoli

XL1blue

• شناسايى زن Pig توسط واكنش PCR

جدول ז. ويثگكى هاى بيوشيميايعى جدايههاى سراشيبا مارسئس حاصل از غربالكرى

\begin{tabular}{ccc}
\hline Results & Biochemical Tests & No. \\
\hline Gram-negative Rod & Gram satin &. \\
+ & Catalase Test &.$r$ \\
+ & Motility test &.$r$ \\
+ & DNase &. \\
- & Oxidase test & $\Delta$ \\
- & Methyl read test & $\mathcal{.}$ \\
+ & Gelatin hydrolysis &.$v$ \\
+ & Growth at 40 „C & $\wedge$ \\
\hline
\end{tabular}

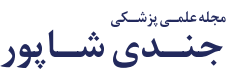



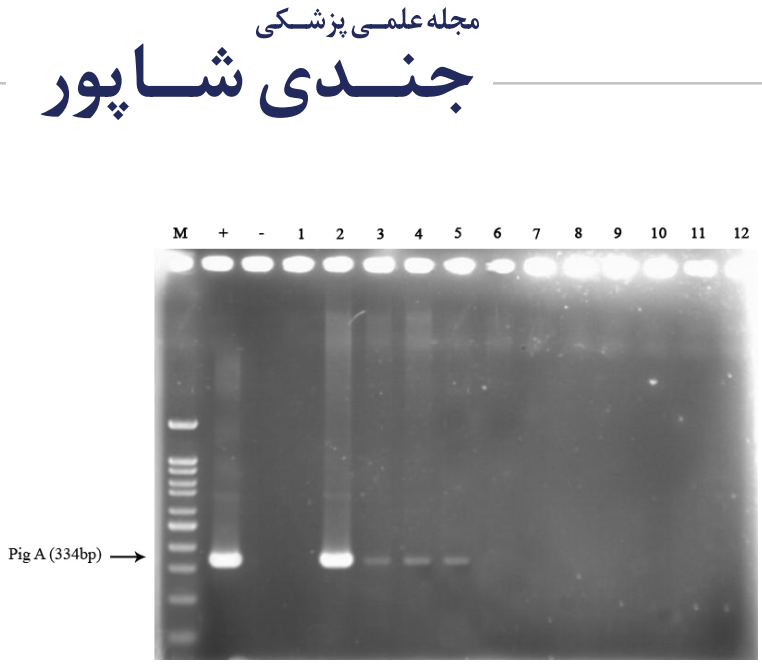

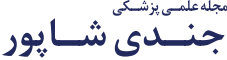

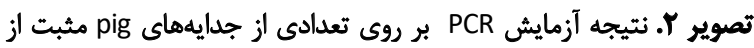

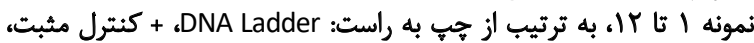

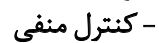

هستئد كه به منظور توليد رنكانه يرودى جيوسين در مطالعات آينده مورد استفاده قرار كيرند. بندين.

ب

سراشيا، باكترى ترم منفى و متحرك و داراى كيسول كوجيكى

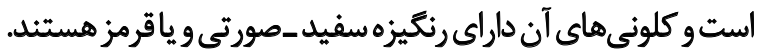

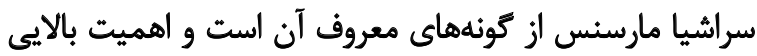
دارد. يرودى جيوسين يك ترى بيرول است و اولين بار در سراشيا

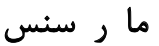

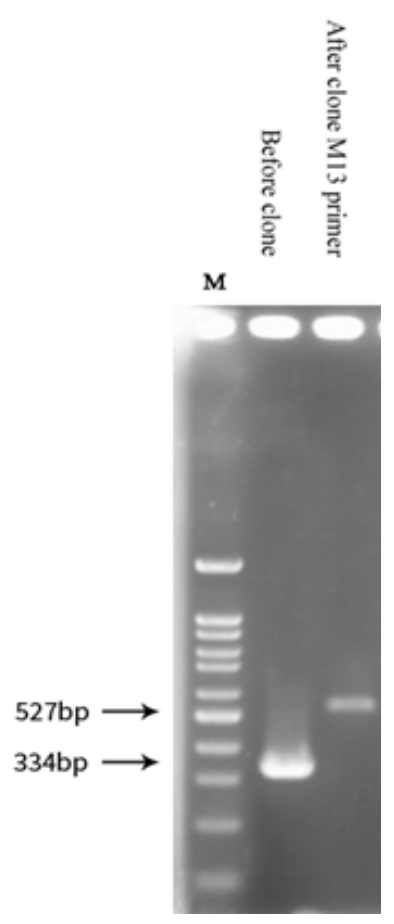

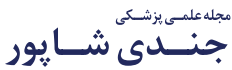

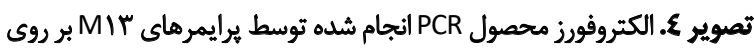

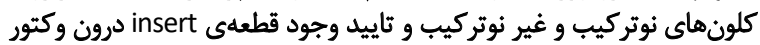
نوتركيب (ظل اكارز ب دوريد)

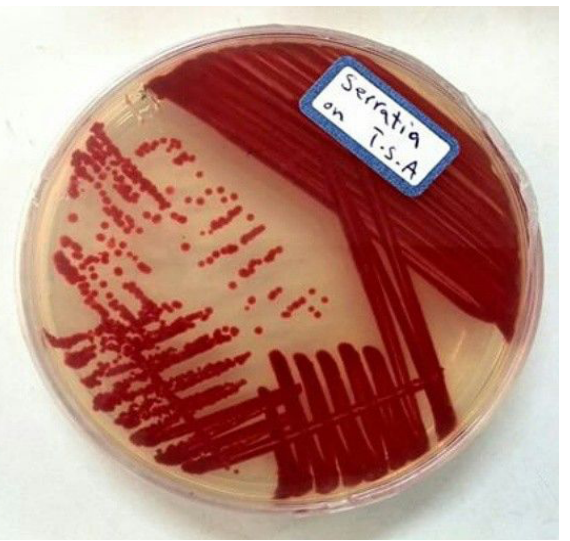

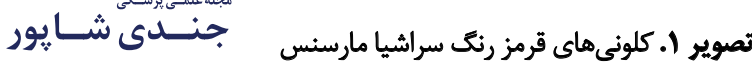
جشمكيرى نشان مى دهد. به طورى كه در نمودار زرد هيج بيانى

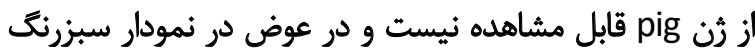

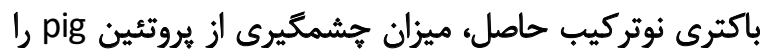
توليد كرده است.

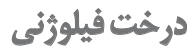

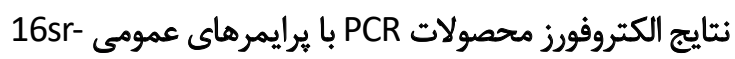

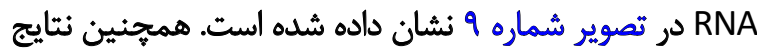
رسم درخت فيلورنتيكى در تصوير شماره

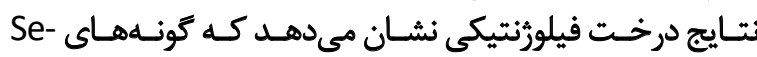

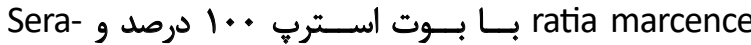
tia palmy uthica

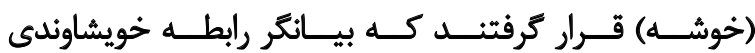

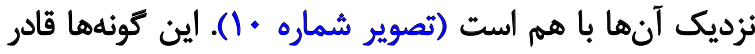

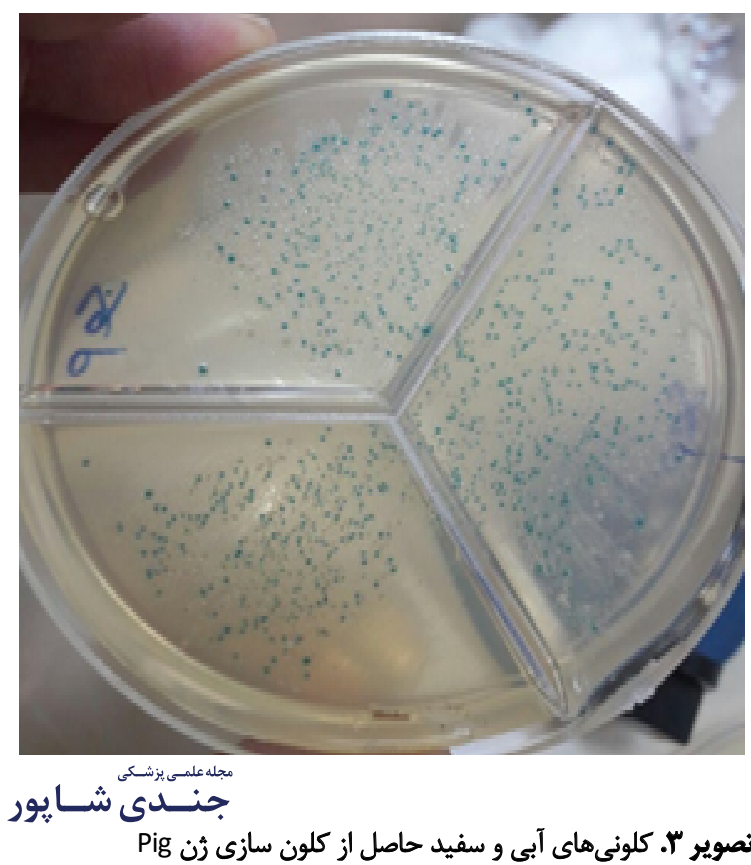




\section{Bioneer $_{2: F}$}

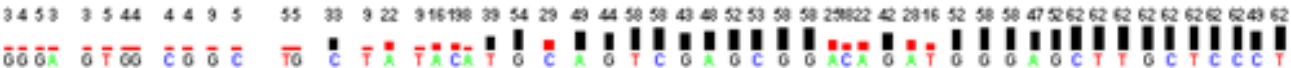

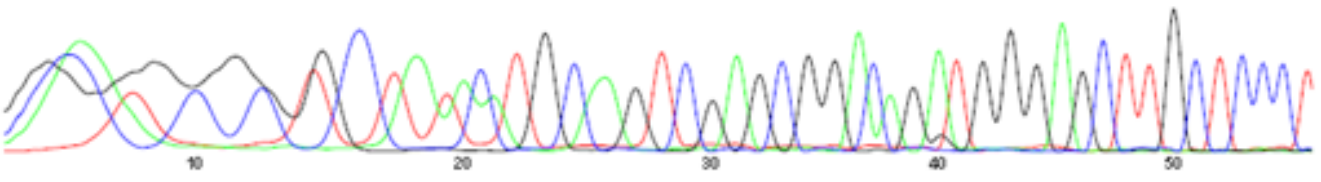

1.

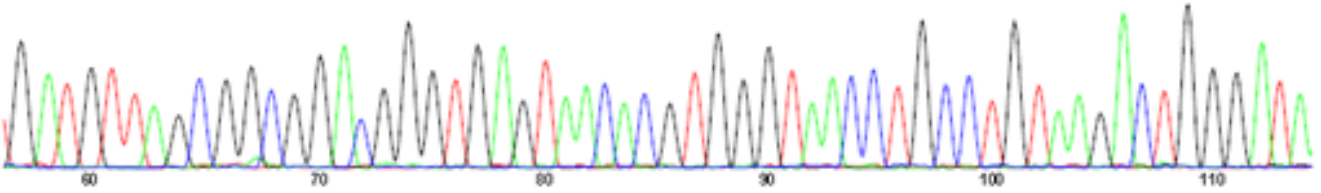

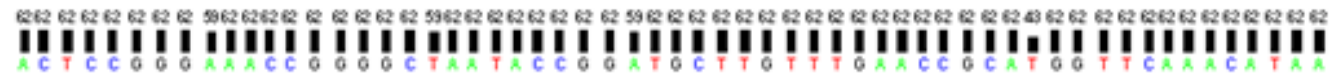

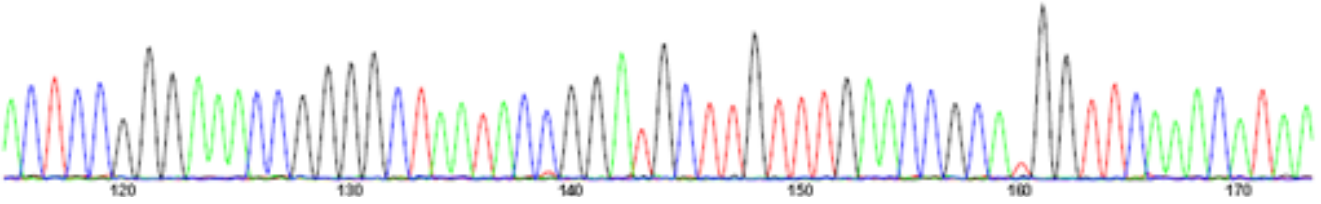

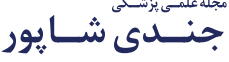

تصوير 0. نتيجه سكانس و بلاست جهت تعيين هويت مولكولى كونه سراشيا مارسنس

روش SDS-PAGE سنجيدند و ايزولههاى توليدكنيده رنكدانه

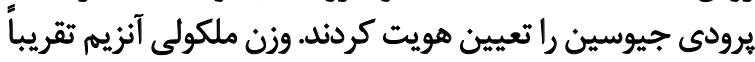

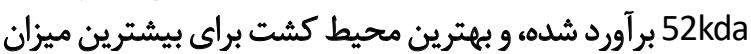

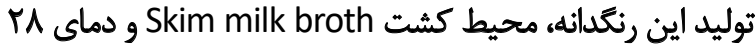

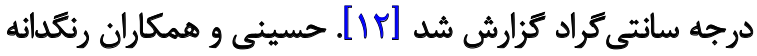

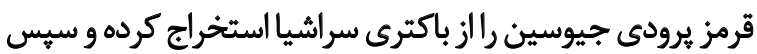

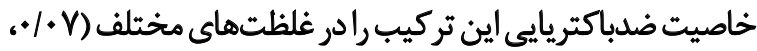

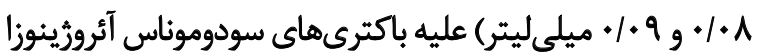

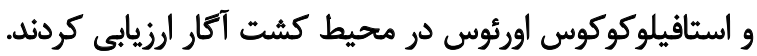

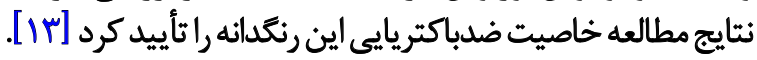

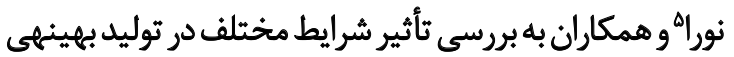

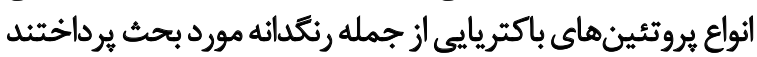

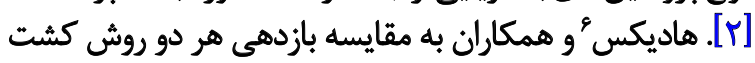

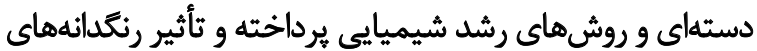

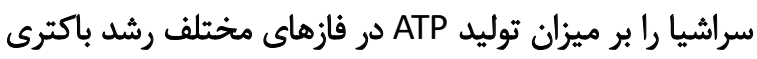

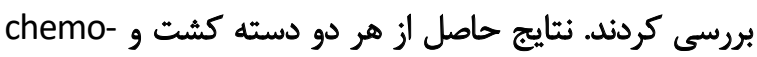

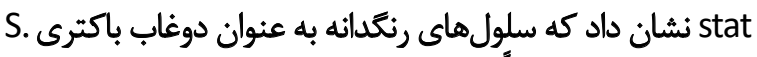

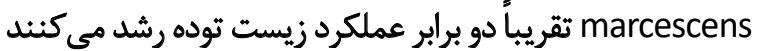

5. Nora

6. Haddix
شناسايي شد كه كلونىهاى قرمز صندوقى شكل زيبايي را ايجاد

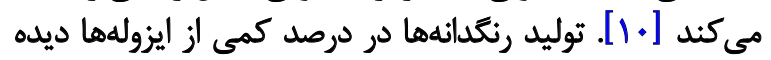

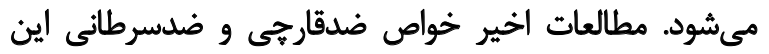

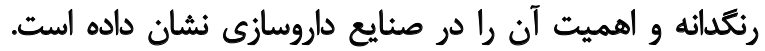

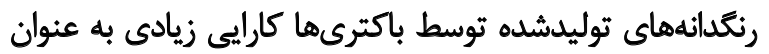

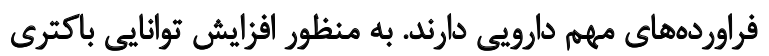

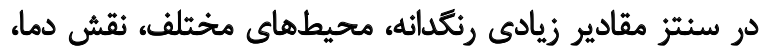

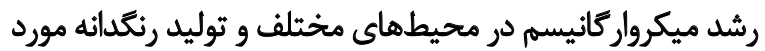

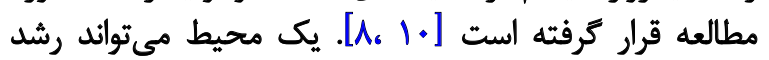

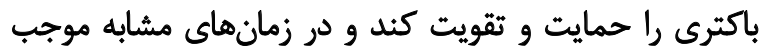

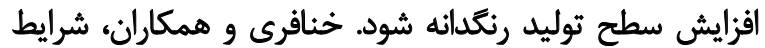

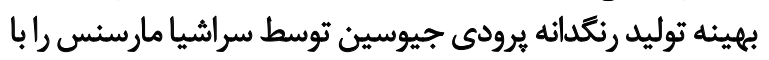

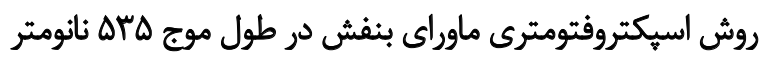

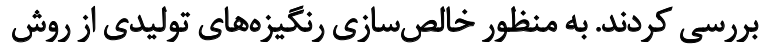

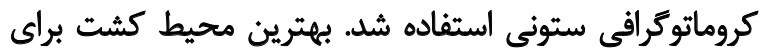

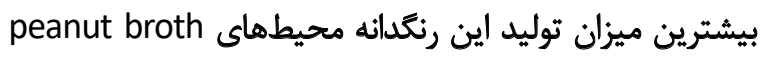

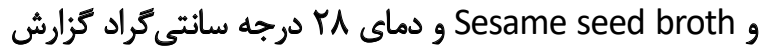

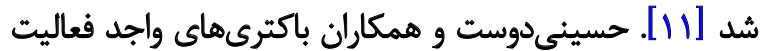

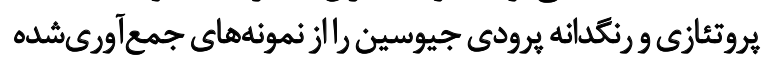

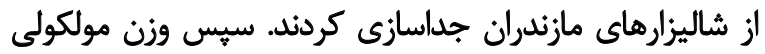

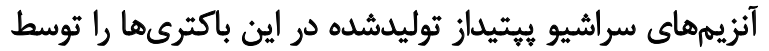



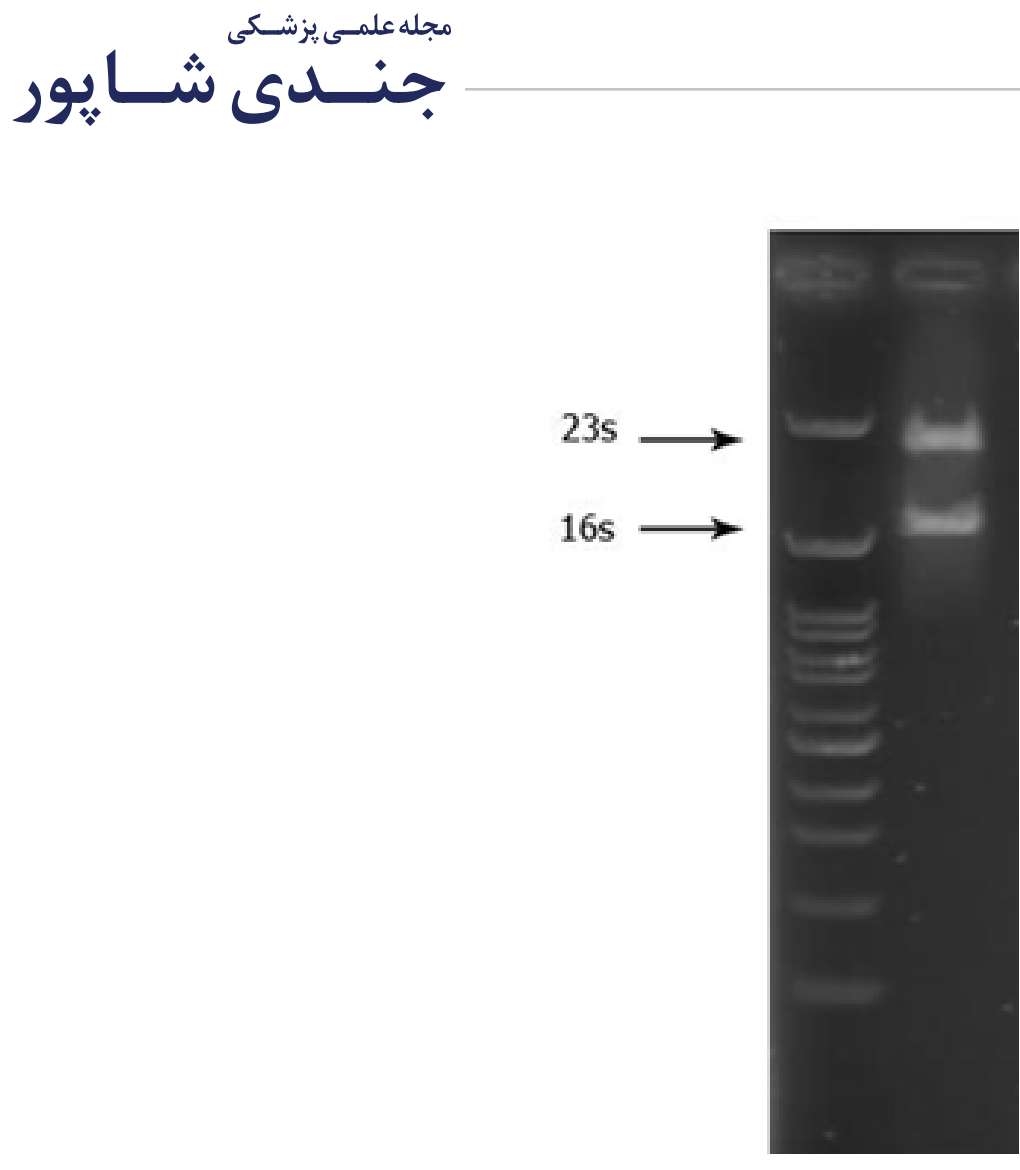

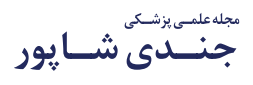

يرودى جيوسين استفاده شد. در اين مطالعه همانند آنجهه در

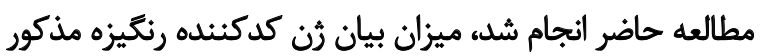

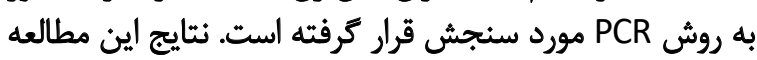

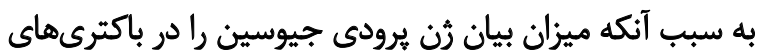

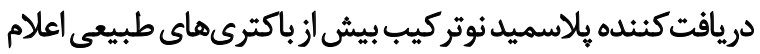

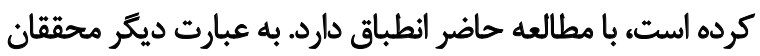

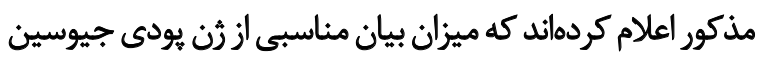

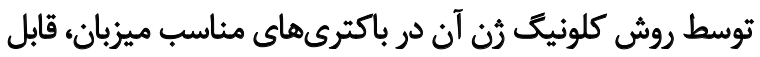

شكل \& الكتروفورز محصول استخراج RNA بر روى ذلّ آكارز ب درصد

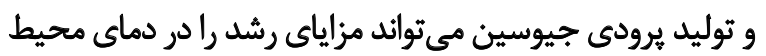

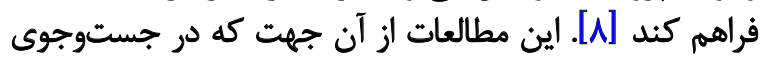

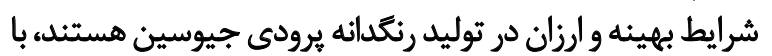
مطالعه حاضر همخواني و انطباق دارند.

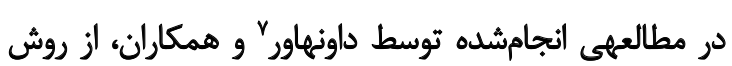

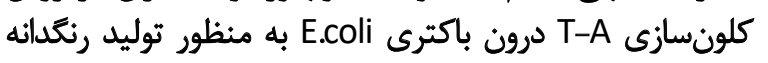

7. Dauenhauer

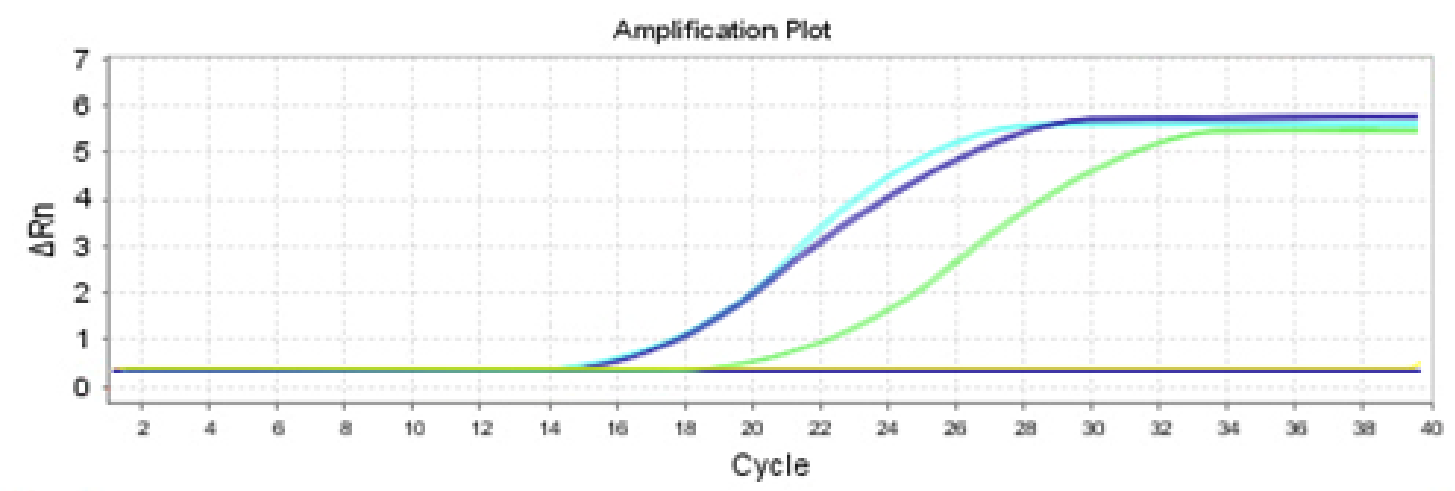




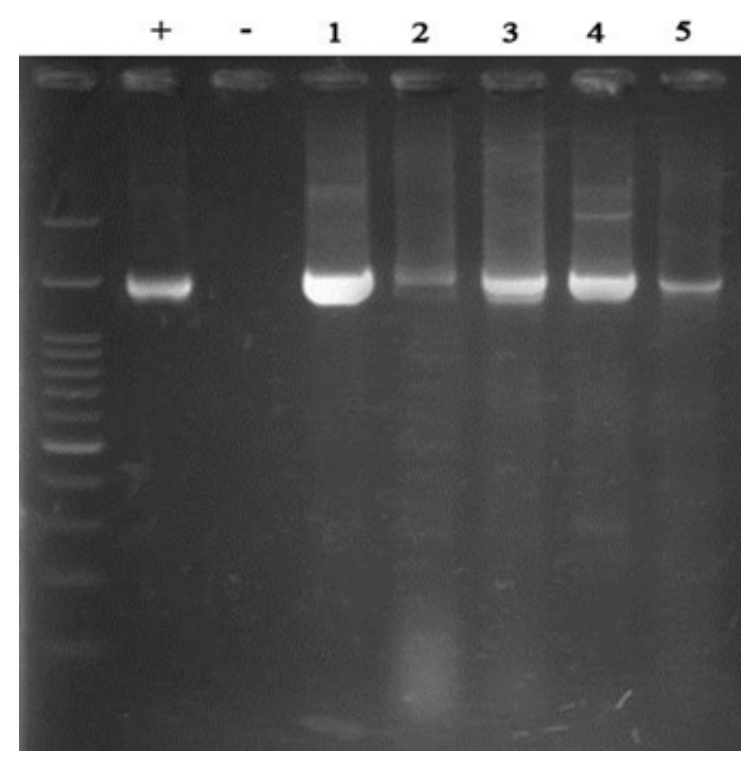

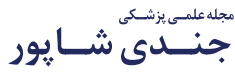

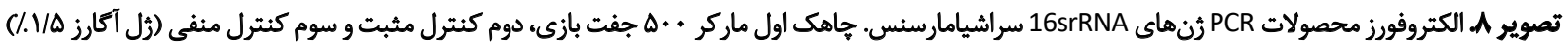

حاضر انطباق دارد. در مطالعه انجامشده توسط هريس و و همكاران

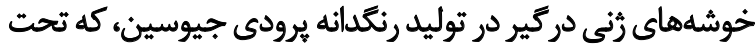

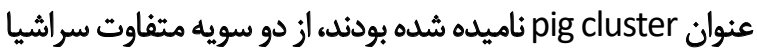

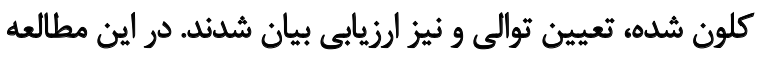

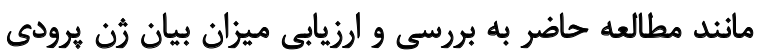

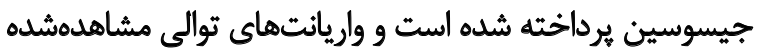
در دو باكترى موردبررسى، جهت ارزيابى روابط ثكاملى آنها و وآنه

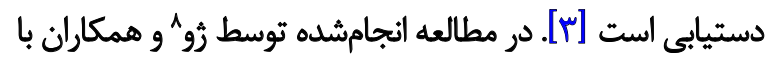

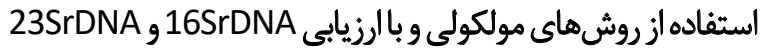

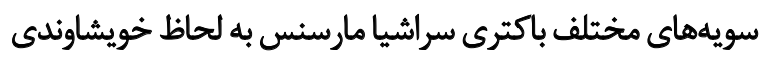

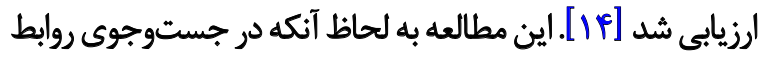

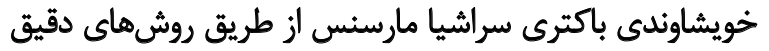

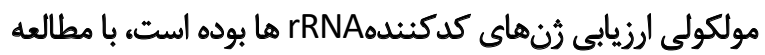

9. Harris

8. Zhu
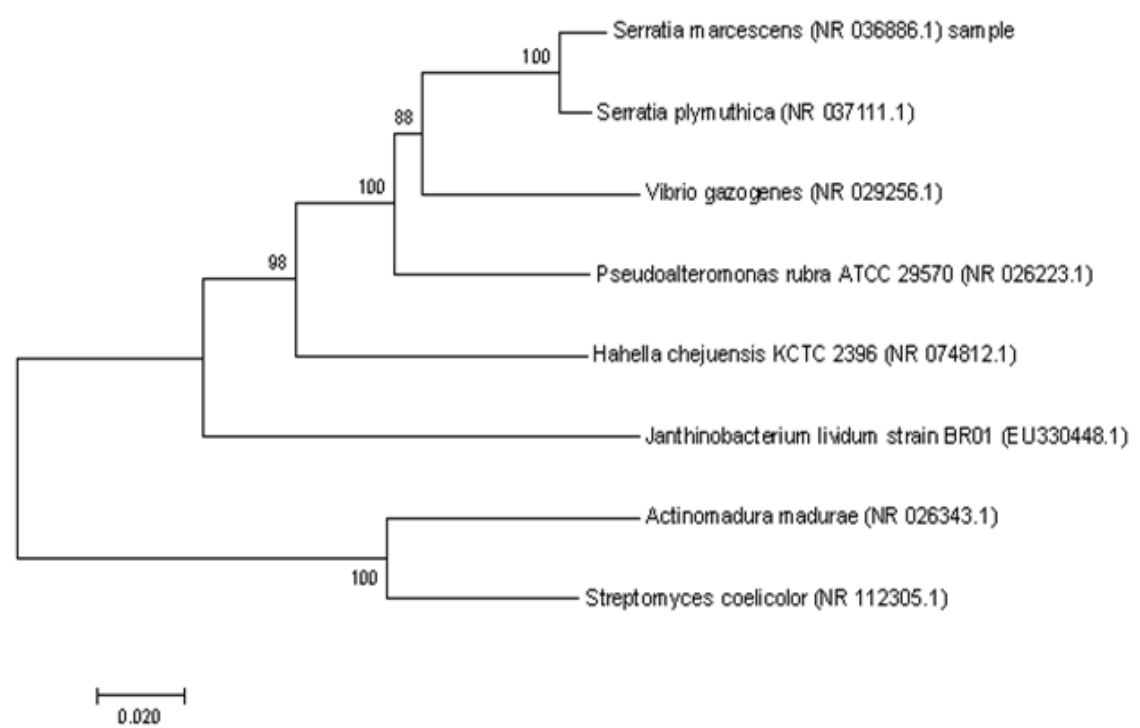

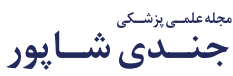

تصوير ج. درخت فيلورنى رسم شده بر اساس توالى ثن 16S r DNA سراشيا مارسنس 


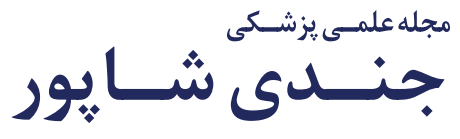

\section{نتيجه}

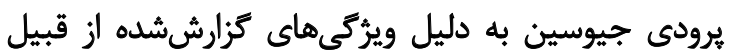

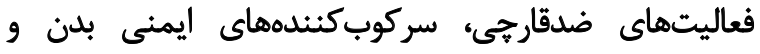

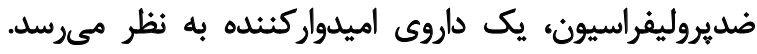

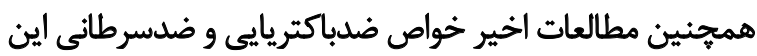

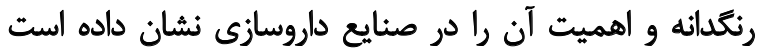

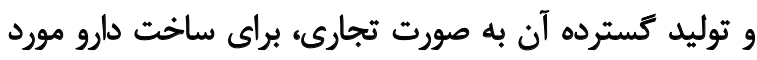

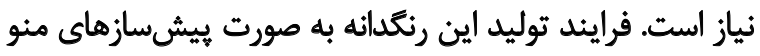

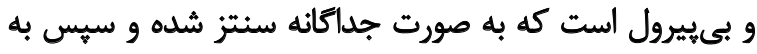

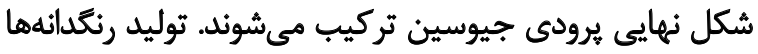

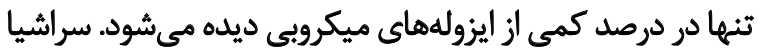

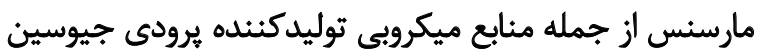

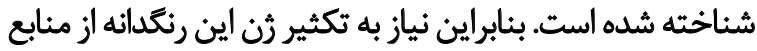

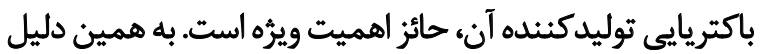

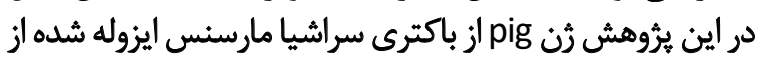

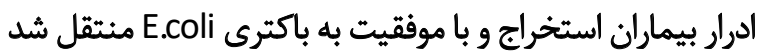

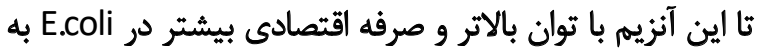

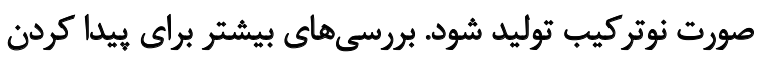

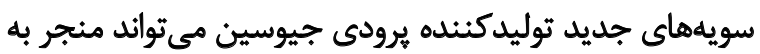

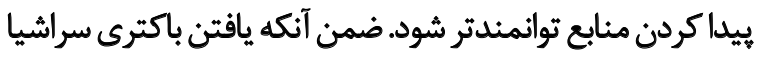

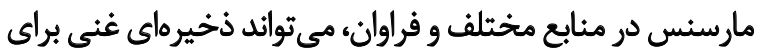
كارخانجات توليدكنئده مواد مفيد زيستى باشد فئد

مالاحظات اخلاقى

$$
\text { يبيروى از اصول اخلاق ئورهش }
$$

اصول اخلاقى تماماً در اين مقاله رعايت شده است.

$$
\text { مامى مالى }
$$

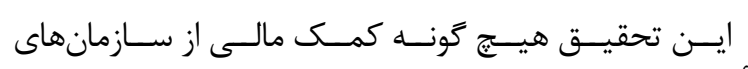

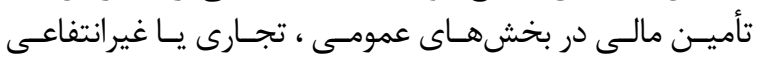

$$
\text { دريافت نكـــد دأمين }
$$

$$
\text { مشار كت نويسئدكان }
$$

هر دو نويسنده در طراحى، اجرا و نكارش همه بخشهاى يزوهش حاضر مشاركت داشتهاند.

$$
\text { تعارض مناقع }
$$

بنابر اظهار نويسندكان اين مقاله تعارض منافع ندارد.

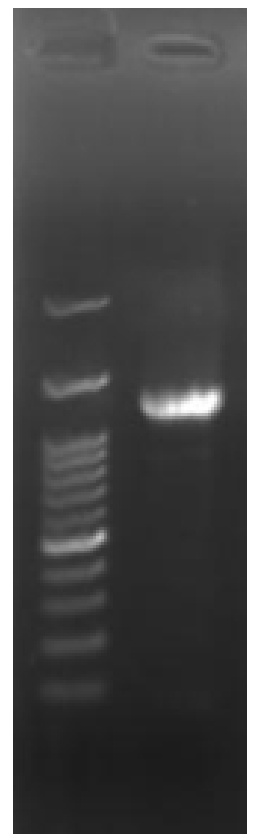

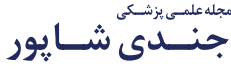

تصوير +1. نتيجه آزمون PCR با يرايمرهاى عمومى 16SrRNA به منظور

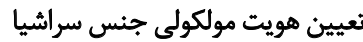

ميزان خويشاوندى مورد استفاده قرار ترفته است [10]. در

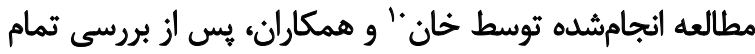

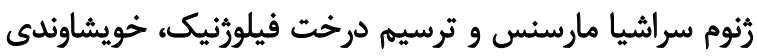

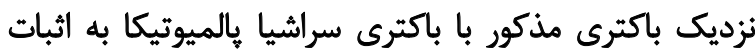

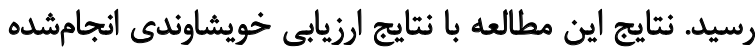

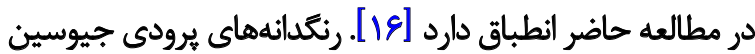

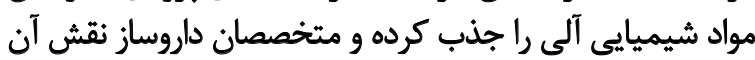

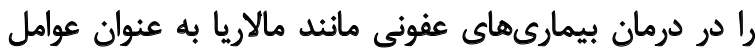

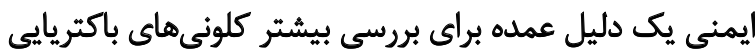

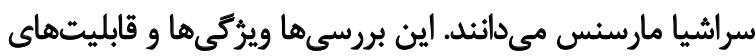

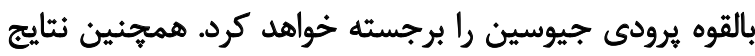

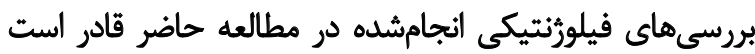

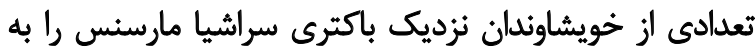

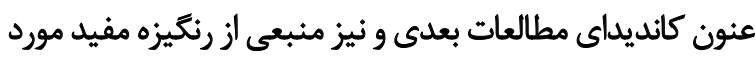

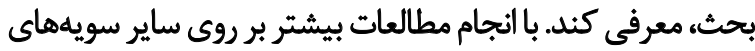

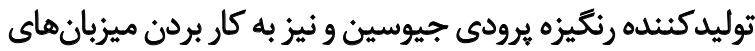

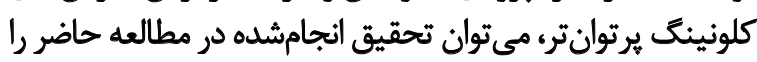

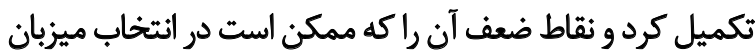

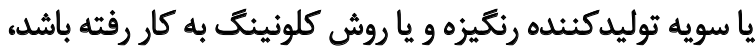

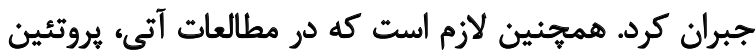

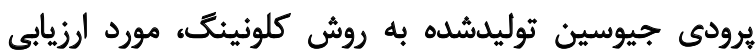
ساختارى و عملكردى قرار تيرد. 


\section{Refrence}

[1] Mahlen SD. Serratia infections: From military experiments to current practice. Clin Microbiol Rev. 2011; 24(4):755-91. [DOI:10.1128/CMR.00017-11] [PMID] [PMCID]

[2] Elkenawy NM, Yassin AS, Elhifnawy HN, Amin MA. Optimization of prodigiosin production by Serratia marcescens using crude glycerol and enhancing production using gamma radiation. Biotechnol Rep. 2017; 14:47-53. [DOI:10.1016/j. btre.2017.04.001] [PMID] [PMCID]

[3] Dauenhauer SA, Hull R, Williams RP. Cloning and expression in Escherichia coli of Serratia marcescens genes encoding prodigiosin biosynthesis. J Bacteriol. 1984; 158(3):1128-32. [DOI:10.1128/jb.158.3.1128-1132.1984] [PMID]

[4] Faraag AH, El-Batal Al, El-Hendawy HH. Characterization of prodigiosin produced by Serratia marcescens strain isolated from irrigation water in Egypt. Nat Sci. 2017; 15(5):55-68. [DOI:10.7537/marsnsj150517.08]

[5] Venil CK, Lakshmanaperumalsamy P. An insightful overview on microbial pigment, prodigiosin. Electron J Biol. 2009; 5(3):49-61. https://ejbio.imedpub.com/an-insightful-overview-on-microbial-pigment-prodigiosin. . php?aid=5945

[6] Brisse S, Verhoef J. Phylogenetic diversity of Klebsiella pneumoniae and Klebsiella oxytoca clinical isolates revealed by randomly amplified polymorphic DNA, gyrA and parC genes sequencing and automated ribotyping. Int J Syst Evol Microbiol. 2001; 51(3):915-24. [DOI:10.1099/00207713-51-3-915] [PMID]

[7] Saha S, Thavasi R, Jayalakshmi S. Phenazine pigments from Pseudomonas aeruginosa and their application as antibacterial agent and food colourants. Res J Microbiol. 2008; 3(3):122-8. [DOI:10.3923/jm.2008.122.128]

[8] Haddix PL, Shanks RMQ. Prodigiosin pigment of Serratia marcescens is associated with increased biomass production. Arch Microbiol. 2018; 200(7):989-99. [DOI:10.1007/s00203-0181508-0] [PMID] [PMCID]

[9] Priya KA, Satheesh S, Ashokkumar B, Varalakshmi P, Selvakumar G, Sivakumar N. Antifouling activity of prodigiosin from estuarine isolate of Serratia marcescens CMST 07. In: Velu R, editor. Microbiological Research in Agroecosystem Management. New Delhi: Springer; 2013. pp. 11-21. [DOI:10.1007/978-81322-1087-0_2]

[10] Ghaith DM, Zafer MM, Ismail DK, Al-Agamy MH, Bohol MFF, AlQahtani A, et al. First reported nosocomial outbreak of Serratia marcescens harboring bla ${ }_{I M P-4}$ and bla $\mathrm{bl}_{\mathrm{VIM-2}}$ in a neonatal intensive care unit in Cairo, Egypt. Infect Drug Resist. 2018; 11:2211-7. [DOI:10.2147/IDR.S174869] [PMID] [PMCID]

[11] Giri AV, Anandkumar N, Muthukumaran G, Pennathur G. A novel medium for the enhanced cell growth and production of prodigiosin from Serratia marcescens isolated from soil. BMC Microbiol. 2004; 4:11. [DOI:10.1186/1471-2180-4-11] [PMID] [PMCID]

[12] Al-Ansari M, Alkubaisi N, Vijayaragavan P, Murugan K. Antimicrobial potential of Streptomyces sp. to the Gram positive and Gram negative pathogens. J Infect Public Health. 2019; 12(6):861-6. [DOI:10.1016/j.jiph.2019.05.016] [PMID]
[13] de Lima Procópio RE, da Silva IR, Martins MK, de Azevedo JL, de Araújo JM. Antibiotics produced by Streptomyces. Braz J Infect Dis. 2012; 16(5):466-71. [DOI:10.1016/j.bjid.2012.08.014] [PMID]

[14] Zhu H, Zhou WY, Xu M, Shen YL, Wei DZ. Molecular characterization of Serratia marcescens strains by RFLP and sequencing of PCR-amplified 16S rDNA and 16S-23S rDNA intergenic spacer. Lett Appl Microbiol. 2007; 45(2):174-8. [DOI:10.1111/ j.1472-765X.2007.02166.x] [PMID]

[15] Harris AKP, Williamson NR, Slater H, Cox A, Abbasi S, Foulds I, et al. The Serratia gene cluster encoding biosynthesis of the red antibiotic, prodigiosin, shows species-and strain-dependent genome context variation. Microbiology. 2004; 150(11):3547-60. [DOI:10.1099/mic.0.27222-0] [PMID]

[16] Khan AR, Park GS, Asaf S, Hong SJ, Jung BK, Shin JH. Complete genome analysis of Serratia marcescens RSC-14: A plant growth-promoting bacterium that alleviates cadmium stress in host plants. PloS One. 2017; 12(2):e0171534. [DOI:10.1371/ journal.pone.0171534] [PMID] [PMCID] 